\title{
Parkia biglobosa aqueous extract ameliorates risk markers of cardiometabolic diseases in spironolactone treated and high-salt fed Sprague- Dawley male rat
}

\section{Adewumi Oyabambi}

University of llorin

\section{Akinjide Akinnuga}

University of Kwazulu-Natal

\section{Success Echibiri}

University of llorin

Aminat Imam-Fulani

University of llorin

Abdulbasit Abdulsalam

University of llorin

Olufemi Oluranti ( $\sim$ olufemi.oluranti@bowen.edu.ng )

Bowen University https://orcid.org/0000-0001-8894-3254

\section{Research Article}

Keywords: Parkia biglobosa, High-salt diet, Spironolactone, Cardiometabolic diseases, Sprague-Dawley rats

Posted Date: January 7th, 2022

DOI: https://doi.org/10.21203/rs.3.rs-1208170/v1

License: (c) (i) This work is licensed under a Creative Commons Attribution 4.0 International License. Read Full License 


\section{Abstract}

Background: The numbers of people with salt-sensitive hypertension and cardiometabolic diseases (CMD) are increasing due to high-salt diet (HSD) consumption globally. Parkia biglobosa (PB), an African locust bean tree, has been reported to have several cardiovascular protective properties but its ameliorative effects on CMD are scarcely reported. Therefore, this study aimed at investigating the effects of PB stem bark aqueous extract on some risk markers of CMD in weanling male rats subjected to HSD and Spironolactone (Sp) treatment.

Twenty-five weanling male rats (95-105 g) were divided into 5 groups: Group 1 (Control); Group 2 (untreated HSD) fed on normal chow and HSD (8\% NaCl); Group 3 (HSD+Sp); Group 4 (HSD+PB); Group 5 $(\mathrm{HSD}+\mathrm{Sp}+\mathrm{PB})$ fed on HSD $(8 \% \mathrm{NaCl})$ and received either $80 \mathrm{mg} / \mathrm{kg}$ of Sp or $400 \mathrm{mg} / \mathrm{kg}$ of PB and both as treatment, respectively. After 6 weeks of treatment, blood samples and heart were collected from each animal for biochemical analysis.

Results: Administration of both PB and Sp or only PB, significantly decreased the plasma or cardiac adenosine deaminase, xanthine oxidase, C-reactive protein, lipids (except high density lipoprotein), uric acid, sodium, and potassium concentrations. Contrarily, the plasma as well as cardiac nitric oxide and endothelial nitric oxide synthase increased significantly by the same treatment.

Conclusion: Parkia biglobosa or its administration with Spironolactone ameliorates associated-risk markers of cardiometabolic disease which are triggered by high salt diet.

\section{Background}

With salt being a major preservative of food prior to refrigeration, the amount of salt in several foodstuffs have significantly increased and eating habits which include salt consumption have substantially changed in industrialized countries [1]. Therefore, the numbers of people affected by salt-sensitive hypertension and cardiometabolic diseases are growing [1, 2].

High-salt diet (HSD) is a risk factor that has detrimental effects on the tissues and organs of cardiovascular systems [3, 4]. HSD alters the metabolic functions of the body system via increase in plasma sodium concentration and expansion of extracellular volume which subsequently lead to increased blood pressure $[4,5]$. Also, several researches have shown that incessant intake of HSD may result into dysregulations of the cardiovascular systems, leading to fluid overload, inflammation, elevated serum triglyceride and cholesterol, decreased vascular bioavailability of nitric oxide (NO) which cause several endothelial and metabolic dysfunctions in the blood vessels and heart [6-9]. Moreover, studies have shown that HSD triggers elevated uric acid (hyperuricaemia) which is already known as an independent risk factor of cardiometabolic diseases $[10,11]$. In addition, increased activity of adenosine deaminase (ADA) and xanthine oxidase (XO) can be hypothesized to result in hyperuricaemia. However, the association between HSD and these enzymes (ADA and XO) of uric acid metabolism has not been well documented. Studies have shown that both HSD and hyperuricaemia are associated with 
impairment of nitric oxide (NO) production due to inhibition of endothelial nitric oxide synthase (eNOS) $[12,13]$. The human body prevents the risk of developing cardiometabolic dysfunctions and tolerates excessive salt intake for a short time. However, dietary salt reduction and pharmacological interventions are the therapeutic approaches to cardiometabolic diseases, but studies have shown that these approaches are with side effects in certain individuals [14-16]. Therefore, other therapeutic approaches that prevent or manage cardiometabolic dysfunctions due to HSD are necessary. As a result, the quest for other approaches has presented traditional alternative medicine as an effective, safe, and inexpensive therapy.

Parkia biglobosa (PB) is a multipurpose fodder tree that belongs to the family Mimosaceae, popularly called the "African locust bean tree". PB is found in many countries, especially in the West African coast where the seeds are fermented into locust beans (known as "iru" in Yoruba, "dawadawa" in Hausa, and "ogiriokpe" in Igbo), a popular local food seasoning known to be rich in protein and vitamin B2. Though the seed, leaf, and stem bark extracts of PB have been shown to exhibit hypotensive activities by decreasing blood pressure via vasodilation $[17,18]$. Apart from the reported hypotensive activities of PB, there is scarce information on the effects of the aqueous extract of PB stem bark in relations to other risk factors or markers of cardiometabolic functions. Therefore, this study was designed to investigate the effects of the aqueous extract of PB stem bark on some risk factors or markers which are associated with cardiometabolic diseases in weanling Sprague-Dawley male rats that are subjected to HSD.

\section{Methods}

\subsection{Plant material and extract preparation}

The stem barks of Parkia biglobosa (PB) were collected from the PB trees in the University of Ilorin, College of Health Sciences premises, and air dried in a shade. The plant was identified and authenticated by Mr BoluAjayi of the Department of Plant Biology, University of Ilorin, with voucher number UILH|001|2019|1016. Also, the phytochemical contents (Sample label and Serial number: MTL/14920/009) of the stem bark were analysed at the Molecular Toxicology Laboratory, Biochemistry Department, Obafemi Awolowo University, Ile-Ife, Nigeria as described in Table 1. 
Table 1

Phytochemical contents of PB stem bark

\begin{tabular}{|ll|}
\hline Parameter Measured & Value Obtained \\
\hline Alkaloid & $5.297 \pm 0.334 \mathrm{mgAE} / \mathrm{g}$ \\
\hline Tannin & $5.517 \pm 0.885 \mathrm{mgGAE} / \mathrm{g}$ \\
\hline Phenol & $129.443 \pm 3.311 \mathrm{mgGAE} / \mathrm{g}$ \\
\hline Flavonoid & $30.667 \pm 4.225 \mathrm{mgQUE} / \mathrm{g}$ \\
\hline mgAE/g= milligrams ascorbic acid equivalent per gramme of sample \\
\hline mgGAE/g= milligrams Gallic acid equivalent per gramme of sample \\
\hline mgQUE/g= milligrams Quercetin acid equivalent per gramme of sample \\
\hline
\end{tabular}

The air-dried stem barks were grinded into powder using a milling machine and then sieved. For conventional extraction, $5 \mathrm{~g}$ of the powdered stem bark was soaked in $50 \mathrm{~mL}$ of distilled water in a beaker for 48 hrs and stirred intermittently every 2-3 hours to mix properly. This process was repeated until the desired amount of residue was obtained. At the end of the 48 hours, the solution was filtered with a Whitman filter paper $(125 \mathrm{~mm})$ to separate the residue from the filtrate. Thereafter, the filtrate was filtered and concentrated into a powdery form via water bath at $40^{\circ} \mathrm{C}$, and $400 \mathrm{mg} / \mathrm{kg}$ was administered as the dose of the aqueous extract according to Tijani et al [19].

A gas chromatography-mass spectrometer (GC-MS) was used to separate the chemical mixture and analyzed different chemical constituents of the aqueous extract of PB stem bark as described in Table 2 and GC-MS trace in Figure 1.

\section{Table 2: Gas chromatography and Mass spectrometer}

A GC-MS was used for the instrumental analysis of Pakia biglobosa tree bark extract which showed major compounds peaking at different times, majorly dodecanoic acid and 1,2,3-propanetriol ester at various resident times (RT) as shown below 


\begin{tabular}{|c|c|c|c|}
\hline Chemical constituent & Resident time (RT) & $\%$ Area concentration & Peak height \\
\hline \multirow[t]{16}{*}{ Dodecanoic acid } & 13.384 & 5.85 & 11539468 \\
\hline & 13.835 & 5.90 & 14955791 \\
\hline & 14.708 & 7.90 & 20141357 \\
\hline & 14.933 & 6.29 & 20697431 \\
\hline & 15.187 & 6.97 & 19511014 \\
\hline & 15.694 & 5.40 & 16003563 \\
\hline & 16.004 & 6.23 & 14774676 \\
\hline & 16.483 & 8.26 & 13336278 \\
\hline & 16.736 & 5.03 & 13877632 \\
\hline & 16.849 & 1.54 & 12732811 \\
\hline & 17.018 & 5.98 & 15093299 \\
\hline & 17.299 & 4.84 & 12706034 \\
\hline & 17.638 & 2.74 & 7272968 \\
\hline & 18.004 & 2.42 & 5501031 \\
\hline & 18.342 & 1.71 & 4905644 \\
\hline & 18.736 & 0.91 & 1347430 \\
\hline \multirow[t]{8}{*}{ 1, 2, 3-Propanetriy 1 ester } & 14.933 & 6.29 & 20697431 \\
\hline & 15.187 & 6.97 & 19511014 \\
\hline & 16.483 & 8.26 & 13336278 \\
\hline & 16.736 & 5.03 & 13877632 \\
\hline & 17.018 & 5.98 & 15093299 \\
\hline & 17.638 & 2.74 & 7272968 \\
\hline & 18.004 & 2.42 & 5501031 \\
\hline & 18.736 & 0.91 & 1347430 \\
\hline
\end{tabular}

\subsection{Experimental animals}

Twenty-five (25) weanling Sprague-Dawley male rats that weighed between 95-105 g were obtained from the animal house of the College of Health Sciences, University of Ilorin, Nigeria. The animals were acclimatized for 2 weeks and maintained under standard environmental conditions of temperature (22$26^{\circ} \mathrm{C}$ ), relative humidity (50-60\%) and 12-hour dark/light cycle. The study was carried out according to the 
National Institutes of Health's Guide for the Care and Use of Laboratory Animals and was approved by the Ethical Review Committee of the University of Ilorin (UERC) with ethical number UERC/ASN/2019/357.

\subsection{Treatment and experimental design}

Spironolactone (Sp), a reference drug, was purchased from Sigma-Aldrich (95\% purity level) and administered at a dose of $80 \mathrm{mg} / \mathrm{kg}$ according to Sica [14]. After 2 weeks of acclimatization, the weanling animals were randomly assigned into five groups $(n=5)$, fed on normal chow or high-salt diet (HSD, 8\% $\mathrm{NaCl}$ ) as described by Sofola et al [20] and received either Sp or PB extract and both as treatment for 6 weeks as follows:

Group 1 (Control): normal chow and $2 \mathrm{~mL}$ of distilled water (vehicle).

Group 2 (Untreated HSD): HSD (8\% $\mathrm{NaCl})$ and $2 \mathrm{~mL}$ of distilled water (vehicle).

Group 3 (HSD+Sp): HSD (8\% $\mathrm{NaCl})$ and Sp $(80 \mathrm{mg} / \mathrm{kg})$ as treatment.

Group 4 (HSD+PB): HSD (8\% $\mathrm{NaCl})$ and PB aqueous extract $(400 \mathrm{mg} / \mathrm{kg})$ as treatment.

Group 5 (HSD+Sp+PB): HSD (8\% NaCl) and both Sp and PB aqueous extract as treatment.

\subsection{Blood sample collection and tissue harvesting}

At the end of the treatment period, the animals were anaesthetized by intraperitoneal injection of sodium pentobarbital (50 mg/kg). While the animals were unconscious, blood samples were collected by cardiac puncture into heparinized tubes. Also, the heart was excised from eachanimal, rinsed in normal saline, weighed, and corrected to body weight to eliminate variability. The blood samples were centrifuged at 3000 rpm for 15 min to obtain plasma, and the plasma was stored frozen until needed for biochemical assay. Thereafter, $100 \mathrm{mg}$ of the heart tissues were homogenized in cold phosphate buffer solution by homogenizer, and subsequently centrifuged at $10000 \mathrm{rpm}$ for $10 \mathrm{~min}$ at $40^{\circ} \mathrm{C}$.

\subsection{Determination of relative weight}

The relative weights of the heart of the animals were determined from the percentage of the ratio of the heart weight to the body weight i.e.

Relative weight $=$ heart weight $/$ body weight $\times 100$

\subsection{Biochemical Analysis}

The biochemical analysis of sodium, potassium, total cholesterol (TC), triglycerides (TG), high density lipoprotein (HDL), nitric oxide (NO), endothelial nitric oxide synthase (eNOS), uric acid (UA), c-reactive protein (CRP), xanthine oxidase (XO), adenosine deaminase (ADA) concentrations were determined via standardized enzymatic colorimetric methods by using specific assay kits as described in the instruction manuals of the manufacturer (Fortress diagnostics, Antrim, UK). The LDL was estimated by the Friedewald's formula (21), LDL = Total cholesterol - (HDL + Triglyceride / 5). 


\subsection{Statistical Analysis}

All data were expressed as means \pm SEM. Statistical data was analyzed with SPSS statistical software. One-way analysis of variance (ANOVA) was used to compare the mean values of variables among the groups. Bonferroni's test was used to identify the significance of pair wise comparisons of mean values among the groups. Statistically significant differences were accepted at $p<0.05$.

\section{Results}

\subsection{Effects on relative heart weight}

The relative heart weight of the untreated HSD-fed rats and HSD-fed rats that received Sp treatment was significantly increased when compared to that of the control group and HSD-fed rats that received PB extract or both PB and Sp, as indicated in Table 3. However, administration of both PB extract and Sp in the presence of HSD significantly decreased the relative heart weight when compared to the control group and HSD-fed rats that received PB extract only. 
Table 3

Effect of Parkiabiglobosa on relative heart weight, mean body weight, food and water intakes in spironolactone treated and high-salt fed male rats

\begin{tabular}{|c|c|c|c|c|c|}
\hline & CTR & HSD & HSD+Sp & HSD+PB & HSD+Sp+PB \\
\hline $\begin{array}{l}\text { Relative heart weight } \\
\text { (\%) }\end{array}$ & $0.62 \pm 0.05$ & $0.75 \pm 0.04^{\star}$ & $0.86 \pm 0.18^{*}$ & $0.64 \pm 0.05 \#$ & $0.55 \pm 0.13 \#$ \\
\hline \multicolumn{6}{|l|}{ Body weight(g) } \\
\hline Initial & $\begin{array}{l}101.00 \pm \\
4.39\end{array}$ & $100.13 \pm 4.07$ & $\begin{array}{l}100.30 \pm \\
3.04\end{array}$ & $\begin{array}{l}102.00 \pm \\
3.29\end{array}$ & $\begin{array}{l}103.20 \pm \\
1.80\end{array}$ \\
\hline Final & $150.50 \pm 8.84$ & $\begin{array}{l}182 . \\
90 \pm 3.20 *\end{array}$ & $\begin{array}{l}166.50 \\
\pm 3.14 \#\end{array}$ & $\begin{array}{l}163.85 \pm \\
7.43 \#\end{array}$ & $\begin{array}{l}145.50 \pm \\
2.60 \#\end{array}$ \\
\hline$\%$ Change & $49.01 \pm 0.40$ & $\begin{array}{l}82.66 \pm \\
0.20 *\end{array}$ & $\begin{array}{l}66.00 \pm \\
0.70 * \#\end{array}$ & $\begin{array}{l}60.64 \pm \\
0.10 \star \#\end{array}$ & $\begin{array}{l}40.99 \pm \\
0.50 \# \beta\end{array}$ \\
\hline \multicolumn{6}{|l|}{$\begin{array}{l}\text { Food } \\
\text { Intake(g/kg/day) }\end{array}$} \\
\hline Initial & $83.40 \pm 2.30$ & $82.40 \pm 1.30$ & $\begin{array}{l}82.20 \pm \\
1.20\end{array}$ & $81.57 \pm 3.10$ & $84.40 \pm 1.40$ \\
\hline Final & $\begin{array}{l}100.90 \pm \\
2.50\end{array}$ & $\begin{array}{l}110.40 \pm \\
2.10\end{array}$ & $\begin{array}{l}104.51 \pm \\
2.40\end{array}$ & $\begin{array}{l}103.20 \pm \\
1.50\end{array}$ & $\begin{array}{l}103.40 \pm \\
2.40\end{array}$ \\
\hline \%Change & $20.98 \pm 2.10$ & $\begin{array}{l}33.98 \pm \\
2.20^{\star}\end{array}$ & $\begin{array}{l}27.14 \pm \\
2.10 \#\end{array}$ & $\begin{array}{l}26.52 \pm \\
1.15 \#\end{array}$ & $\begin{array}{l}22.51 \pm \\
1.30 \#\end{array}$ \\
\hline \multicolumn{6}{|l|}{$\begin{array}{l}\text { Water } \\
\text { Intake(ml/kg/day) }\end{array}$} \\
\hline Initial & $50.90 \pm 4.10$ & $55.60 \pm 3.20$ & $\begin{array}{l}52.60 \pm \\
4.50\end{array}$ & $53.40 \pm 2.60$ & $51.30 \pm 5.30$ \\
\hline Final & $55.70 \pm 5.30$ & $\begin{array}{l}85.70 \pm \\
6.60^{*}\end{array}$ & $\begin{array}{l}65.30 \pm \\
5.50\end{array}$ & $70.00 \pm 5.90$ & $\begin{array}{l}61.20 \pm \\
6.10 \#\end{array}$ \\
\hline \%Change & $9.43 \pm 2.20$ & $\begin{array}{l}54.13 \pm \\
3.10^{*}\end{array}$ & $\begin{array}{l}24.14 \pm \\
2.30 * \#\end{array}$ & $\begin{array}{l}31.09 \pm \\
5.92^{\star} \#\end{array}$ & $\begin{array}{l}19.29 \pm \\
3.70^{\star} \#\end{array}$ \\
\hline $\begin{array}{l}\text { Data were analyzed by } \\
\text { as mean } \pm \text { SEM }(n=5) \\
{ }^{*} p<0.05 \text { (vs HSD grou }\end{array}$ & $\begin{array}{l}\text { ne-way ANOVA } \\
d p<0.05 \text { was } \\
\beta_{p}<0.05 \text { (vs Hs }\end{array}$ & $\begin{array}{l}\text { followed by Bo } \\
\text { aken as statisti } \\
D+S p \text { group). }\end{array}$ & $\begin{array}{l}\text { ferroni's PoS } \\
\text { ally significa }\end{array}$ & $\begin{array}{l}\text { c test. Values } \\
0<0.05 \text { (vs co }\end{array}$ & $\begin{array}{l}\text { re expressed } \\
\text { ol group), }\end{array}$ \\
\hline
\end{tabular}

\subsection{Effects on sodium and potassium concentrations}

There was a significant increase in plasma sodium concentration in the untreated HSD-fed rats (HSD Group) when compared to the control group ( $\mathrm{p}<0.05)$. In contrary, administration of only Sp, PB extract or both significantly decreased the plasma sodium concentration when compared to the untreated HSD-fed rats but not significantly different in comparison to control group (Figure 2A). As shown in Figure 2B, administration of only Sp caused a significant increase in plasma potassium concentration in 
comparison to the untreated HSD-fed rats and control group. However, administration of only PB extract or both PB extract and Sp significantly decreased the plasma potassium concentration when compared to the administration of $\mathrm{Sp}$ alone $(\mathrm{p}<0.05)$.

\subsection{Effects on lipid profiles}

In Figure $3 \mathrm{~A}$, Figure $3 \mathrm{~B}$ and Figure $3 \mathrm{C}$ respectively, the plasma concentrations of triglyceride (TG), total cholesterol (TC) and low-density lipoprotein (LDL) were significantly increased in the untreated HSD-fed rats and HSD-fed rats with Sp administration when compared to the control group. On the other hand, only PB extract or both PB extract and Sp significantly decreased the plasma triglyceride, total cholesterol, and low-density lipoprotein in comparison to the untreated HSD-fed rats and HSD-fed rats with $\mathrm{Sp}$ administration only. Moreover, the HDL plasma concentration significantly decreased in the untreated HSD-fed rats and HSD-fed rats with Sp administration when compared to the control group (Figure 3D). In contrary, administration of PB extract or both PB extract and Sp significantly increased the plasma HDL concentration in comparison to the untreated HSD-fed rats.

\subsection{Effects on plasma and cardiac uric acids}

The plasma and cardiac uric acid levels of untreated HSD-fed rats and HSD-fed rats with Sp administration (HSD+Sp) were significantly increased when compared to the control group $(p<0.05)$, as indicated in Figure 4A and 4B. Only PB extract or its combination with Sp significantly decreased the plasma uric acid level in comparison to the untreated HSD-fed rats. However, administration of only PB extract significantly decreased the cardiac uric acid concentration in comparison to the untreated HSDfed rats (Figure 4B).

\subsection{Effects on adenosine deaminase (ADA) and xanthine oxidase (XO)}

The plasma and cardiac activities of ADA were significantly increased in the untreated HSD-fed rats when compared to the control group (Figure 5A and 5B respectively). On the other hand, administration of the combination of both PB extract and Sp significantly decreased the plasma activities of ADA in HSD-fed rats when compared to the untreated HSD-fed rats (HSD group), HSD-fed rats with Sp (HSD+Sp) and HSD-fed rats with PB extract (HSD+PB). In addition, the administration of only PB extract or its combination with Sp significantly decreased the cardiac activities of ADA in HSD-fed rats in comparison to the untreated HSD-fed rats.

Moreover, the plasma and cardiac activities of XO were significantly increased in the untreated HSD-fed rats when compared to the control group (Figure 5C and Figure 5D respectively). However, administration of only PB extract or both PB extract and Sp significantly decreased the plasma and cardiac activities of $\mathrm{XO}$ when compared to the untreated HSD-fed rats, as shown in Figure $5 \mathrm{C}$ and Figure 5D. 


\subsection{Effects on nitric oxide (NO) and endothelial nitric oxide synthase (eNOS)}

The plasma and cardiac concentrations of NO were significantly decreased in the untreated HSD-fed rats and HSD-fed rats that received Sp administration alone when compared to the control group (Figure 6A and Figure 6B respectively). However, administration of only PB extract and its combination with Sp significantly increased the plasma and cardiac NO concentrations in the HSD-fed rats when compared to the untreated HSD-fed rats. Furthermore, the plasma and cardiac concentrations of eNOS were significantly decreased in the untreated HSD-fed rats when compared to the control group, as indicated in Figure $6 \mathrm{C}$ and Figure $6 \mathrm{D}$ respectively. On the other hand, the plasma and cardiac eNOS concentrations were significantly increased in the HSD-fed rats that received PB extract alone or both PB extract andSp when compared to the untreated HSD-fed rats.

\subsection{Effects on C-reactive protein (CRP)}

The plasma and cardiac concentrations of CRP in untreated HSD-fed rats and HSD-fed rats with Sp administrationincreased significantly when compared to the control group (Figure 7A and 7B). In contrary, administration of only PB extract, as well as its combination with Sp significantly decreased the plasma and cardiac concentrations of CRP in comparison to the untreated HSD and HSD+Sp groups.

\section{Discussion}

This study investigated the adverse effects of high salt intake as well as the plausible therapeutic effects of the stem bark of Parkia biglobosa (PB) aqueous extract or Spironolactone (Sp), and both on markers of cardiometabolic functions. Previous experimental studies have shown that the hydroalcoholic extract of PB stem bark caused vasorelaxation and the aqueous extract of the bark decreased the blood pressure $[2,23]$. However, the present study showed that the aqueous extract of PB stem bark ameliorates cardiometabolic dysfunctions in high-salt diet. High-salt diet (HSD) has been reported to cause some cardiometabolic changes such as electrolytes imbalance (especially sodium and potassium imbalance), dyslipidaemia, cardiac dysfunctions and inflammatory responses $[4,5]$.

In this study, HSD caused a significant increase in plasma sodium and a slight but insignificant decrease in potassium concentration. Increased plasma sodium concentration has been known to elicit deleterious cardiometabolic changes which may involve activation of mineralocorticoid receptors. Spironolactone (Sp) is a mineralocorticoid blocking agent that competes with the cytoplasmic aldosterone receptor [14]. Its mechanism of action is to competitively block the epithelial and non-epithelial actions of aldosterone in the distal tubule of the nephron, thus, preventing sodium and water retention, and causing potassium retention. It is not surprising that the administration of $\mathrm{Sp}$ ameliorated plasma concentrations of sodium and caused potassium retention in HSD-fed animals. This observation is consistent with other studies [1, 14]. The potassium-retention effect of Sp in this study was significantly increased in HSD-fed animals and this showed that Sp acted as a potassium sparing diuretic. Therefore, Sp can cause deleterious 
elevation of circulating potassium as an adverse effect if used for therapy in salt-induced cardiometabolic disease. On the other hand, administrations of either only PB extract or both PB extract and Sp normalized the sodium and potassium plasma concentrations in HSD-fed animals. Therefore, it is reasonable to suggest that $\mathrm{PB}$ extract has a mineralocorticoid blocking action since administration of only PB extract normalized plasma sodium and does not spare potassium as inSp administration. We therefore infer that the combination of PB extract and Sp prevented the deleterious increase in potassium level when Sp was administered alone. Thus, PB may be appropriate for co-administration with Sp (as a diuretic) to prevent the potassium-retention effect of Sp.

Moreover, HSD caused a significant decrease in plasma concentration of high-density lipoprotein and a significant increase in plasma concentrations of triglycerides, low density lipoprotein and total cholesterol, thus, showing an overt dyslipidaemia. Dyslipidaemia has been reported in different studies in association with metabolic syndrome, cardiometabolic dysfunction and salt-induced hypertension $[9,24]$. In addition, the mechanism by which HSD increases triglycerides is still controversial but it is well known that high salt intake impairs lipid metabolism [9]. Interestingly, administration of Sp to HSD-fed animals did not normalize dyslipidaemia.

However, administration of only PB extract or both PB extract and Sp ameliorated lipid profile in HSD-fed animals. Evidence in previous studies has shown that the aqueous extract of PB stem bark has antilipidaemic effects due to its component called tannin which reduces hypertriglyceridaemia and hypercholesterolaemia [25-27]. The anti-lipidaemic effects of PB have also been attributed to its hypolipidaemic component called saponins [28]. Therefore, the observed anti-lipidaemic effects of PB in this study agreed with other previous studies [25-28].

Furthermore, CRP is a general marker of inflammation and a risk marker for cardiovascular diseases.CRP plasma concentration increases whenever there is tissue damage in the body due to inflammation (29). Therefore, the significant increase in the plasma and cardiac CRP in both the untreated HSD-fed rats and HSD-fed rats that received Sp indicated that there was occurrence of systemic and cardiac inflammation in both groups. On the other hand, the PB extract caused a significant decrease in the plasma and cardiac CRP in the HSD-fed animals. Hence, this suggests that PB stem bark has anti-inflammatory properties as reported in the findings of Kouadio et al and Nwaehujor et al [30,31].

In this study, HSD disrupts the endothelial function by a decrease in the plasma and cardiac concentrations of nitric oxide (NO) and endothelial nitric oxide synthase (eNOS). In previous studies, reduction in NO has been shown to be strongly associated with increased levels of reactive oxygen species (ROS) which are generated by NADPH oxidase, xanthine oxidase (XO) or uncoupled eNOS within the vascular wall $[32,33]$. These previous studies were corroborated with the observed increase in the cardiac XO and profound reduction of NO and eNOS in the plasma and cardiac tissues of the untreated HSD-fed rats. However, administration of PB extract ameliorated the endothelial function by a significant increase in NO and eNOS. Therefore, we suggest that since PB stem bark has been reported to have antioxidant and anti-inflammatory properties, the production of ROS that disrupts NO and eNOS 
functions was reduced in HSD-fed rat that received either PB extract or both PB extract and Sp. Similarly, the enhancement of endothelial function via NO production because of the antioxidant property of PB is supported by other study [17].

Furthermore, uric acid is known to cause endothelial dysfunction, vascular smooth muscle cell proliferation, increased IL- 6 synthesis, and impairment of nitric oxide production, all of which contribute to the progression of cardiometabolic diseases [34-36]. The administration of PB extract or its combination with $\mathrm{Sp}$ showed a significant decrease in plasma uric acid level with a concurrent decrease in $A D A$ and $X O$. It is expected that a decrease in uric acid levels should be accompanied by a decrease in both $A D A$ and $X O$. This probably suggests that the observed uric acid lowering properties of the PB extract is mediated through the ADA/XO/UA pathway.

\section{Conclusion}

In summary, we suggested that PB stem bark ameliorated risk markers of cardiometabolic diseases in HSD and Sp treated rats via its antioxidant, anti-inflammatory, anti-lipidaemic and uricosuric effects. In addition, these effects might be due to the presence of its secondary metabolites such as tannin, saponin, alkaloid, flavonoid and phenol which have been reported to possess cardio-protective properties. The enhanced electrolyte balance, endothelial function-enhancing activities and UA lowering capacity of PB in this study is worthy of note. Therefore, further studies are needed on the exact mechanisms by which PB exhibit its ameliorative effects in cardiometabolic diseases model.

\section{Abbreviations}

HSD

Cadmium

PB

Parkia biglobosa

CMD

cardio metabolic disease

Sp

Spironolactone

ADA

Adenosine deaminase

XO

Xanthine oxidase

eNOS

epithelial nitric oxide synthase

LDL

Low density lipo-protein

HDL 
High density lipo-protein

NO

Nitric oxide

CRP

C-reactive protein

ROS

Reactive oxygen species

\section{Declarations}

\section{Ethics approval and consent to participate}

The study was approved by the Ethical Review Committee of the University of Ilorin (UERC) with ethical number UERC/ASN/2019/357.

\section{Consent for publication}

Not applicable

\section{Availability of data and materials}

All data generated in this study are included in this article

\section{Competing interests}

The authors declared no potential conflicts of interest with respect to the research, authorship, and/or publication of this article.

\section{Funding}

This research received no specific grant from any funding agency in the public, commercial or not-forprofit sectors

\section{Authors' contributions}

AOO, AMK, SEE and AOA conceived and designed the research. AOO, AMK, SEE and AOA conducted the experiments. AOO, SEE and AOA contributed to the new reagents and analytical kits. AOO, AMK, SEE, OIO and $\mathrm{AOI}$ analyzed and interpreted the data. AOO, AMK, AOI, and OIO drafted the manuscript. All authors read and approved the manuscript, and all data were generated in-house and that no paper mill was used.

\section{Acknowledgement}

The authors acknowledge the HOPE Cardiometabolic Research Team and Mr. Adebowale of Bridge Biotech for providing technical support during the laboratory analysis. 


\section{References}

1. Agócs R, Sugár D, Szabó AJ (2020) Is too much salt harmful? Yes blood pressure dietary approaches to stop hypertension trial of hypertension prevention. Pediatr Nephrol 35: 1777-1785.

2. Bibbins-Domingo K, Chertow GM, Coxson PG, Moran A, Lightwood JM, Pletcher MJ et al. (2010) Projected effect of dietary salt reductions on future cardiovascular disease. N Engl J Med 362: 590599.

3. Farquhar WB, Edwards DG, Jurkovitz CT, Weintraub WS (2015) Dietary sodium and health: More than just blood pressure. J Am Coll Cardiol. 65: 1042-1050.

4. Robinson AT, Edwards DG, Farquhar WB (2019) The influence of dietary salt beyond blood pressure. Curr Hypertens Re. 21: 42-52.

5. Cappuccio FP (2013) Cardiovascular and other effects of salt consumption. Kidney Int Suppl 3: 312-315.

6. Sanders PW (2009) Vascular consequences of dietary salt intake. Am J Physiol Renal Physiol 297: F237-43.

7. Graudal NA, Hubeck-Graudal T, Jurgens G (2011) Effects of low sodium diet versus high sodium diet on blood pressure, renin, aldosterone, catecholamines, cholesterol, and triglyceride. Cochrane Database Syst Rev 11: CD004022.

8. Campino C, Baudrand R, Valdivia CA, Carvajal C, Vecchiola A, Tapia-Castillo A et al. (2018) Sodium intake is associated with endothelial damage biomarkers and metabolic dysregulation. Am J Hypertens 31: 1127-1132

9. Choi JW, Park JS, Lee CH (2020) Interactive effect of high sodium intake with increased serum triglycerides on hypertension. PLoS One 15: e0231707

10. Hou L, Zhang M, Han W, Tang Y, Xue F, Liang S et al. (2016) Influence of salt intake on association of blood uric acid with hypertension and related cardiovascular risk. PLoS One11: e0150451.

11. Wang Y, Chu C, Wang KK, Hu JW, Yan Y, Lv YB et al. (2018) Effect of salt intake on plasma and urinary uric acid levels in Chinese adults: An interventional trial. Sci Rep 8: 1434

12. Choi YJ, Yoon Y, Lee KY, Hien TT, Kang KW, Kim KC et al. (2014) Uric acid induces endothelial dysfunction by vascular insulin resistance associated with the impairment of nitric oxide synthesis. FASEB J 28: 3197-3204.

13. Albu A, Para I, Porojan M (2020) Uric acid and arterial stiffness. Ther Clin Risk Manag 16: 39-54.

14. Sica DA (2005) Pharmacokinetics and pharmacodynamics of mineralocorticoid blocking agents and their effects on potassium homeostasis. Heart Fail Rev 10: 23-29.

15. Alderman MH (2010) Reducing dietary sodium: the case for caution. JAMA. 303: 448-449.

16. Graudal NA, Hubeck-Graudal T, Jürgens G (2016) Reduced dietary sodium intake increases heart rate. A meta-analysis of 63 randomized controlled trials including 72 study populations Front Physiol 7:111. 
17. Tokoudagba J, Auger C, Bréant L, N'Gom S, Chabert P, Idris-Khodja N et al. (2010) Procyanidin-rich fractions from Parkiabiglobosa (Mimosaceae) leaves cause redox-sensitive endothelium-dependent relaxation involving NO and EDHF in porcine coronary artery. J Ethnopharmacol 132: 246-250.

18. Gbolade A (2012) Ethnobotanical study of plants used in treating hypertension in Edo State of Nigeria. J Ethnopharmacol 144: 1-10.

19. Tijani AY, Okhale SE, Salawu TA, Onigbanjo HO, Obianodo LA, Akingbasote JA et al. (2009) Antidiarrhoeal and Antibacterial properties of crude aqueous stem bark extract and fractions of Parkiabiglobosa (Jacq.) R. Br. Ex G. Don. Afr J Pharm Pharmacol 3: 347-353.

20. Sofola OA, Knill A, Hainsworth R, Drinkhill M (2002) Change in endothelial function in mesenteric of arteries of Sprague-Dawley rats fed a high salt diet. J Physiol 543: 255-260

21. Friedewald WT, Levy RI, Fredrickson DS (1972) Estimation of the concentration of low-density lipoprotein cholesterol in plasma, without use of the preparative ultracentrifuge. Clin Chem 18(6): 499-502.

22. Kassi Y, Aka KJ, Abo KJ, Mea A, Bi SAN, Ehile EE (2008) Effetantihypertensif d' un extraitaqueux d' écorce de tronc de Parkiabiglobosa (mimosaceae) sur la pressionartérielle de lapin. Sci Nat 5: 133143.

23. Ouédraogoa S, Somé N, Ouattara S, Kini FB, Traore A, Bucher B et al. (2012) Acute toxicity and vascular properties of seed of Parkiabiglobosa (JACQ) R. Br Gift (Mimosaceae) on rat aorta. Afr J Tradit Complementary Altern Med 9: 260-265

24. Kang YJ, Wang HW, Cheon SY, Lee HJ, Hwang KM, Yoon HS (2016) Associations of obesity and dyslipidemia with intake of sodium, fat, and sugar among Koreans: a qualitative systematic review. Clin Nutr Res 5: 290-304.

25. Odetola AA, Akinloye O, Egunjobi C, Adekunle WA, Ayoola AO (2006) Possible antidiabetic and antihyperlipidaemic effect of fermented Parkiabiglobosa (jacq) extract in alloxan induced diabetic rats. Clin Exp Pharmacol Physiol 33: 808-812.

26. Zou B, Li C, Chen J, Dong X, Zhang Y, Du J (2012) High molecular weight persimmon tannin is a potent hypolipidemic in high-cholesterol diet fed rats. Food Res Int 48: 970-977.

27. Fan H, Wu D, Tian W, Ma X (2013) Inhibitory effects of tannic acid on fatty acid synthase and 3T3-L1 pre-adipocyte. Biochim Biophys Acta 1831: 1260-1266.

28. Xu H, Yu X, Qu S, Chen Y, Wang Z, Sui D (2013) In vivo and in vitro cardioprotective effects of Panax quinquefolium 20 (S)-protopanaxadiol saponins (PQDS), isolated from Panax quinquefolium. Pharmazie 68: 287-292.

29. Yousuf O, Mohanty BD, Martin SS, Joshi PH, Blaha MJ, Nasir K et al. (2013) High- sensitivity Creactive protein and cardiovascular disease. A resolute belief or an elusive link? J Am Coll Cardiol 62: 397-408.

30. Kouadio F, Kanko C, Juge M, Grimaud N, Jean A, N'guessan Y et al. (2000) Analgesic and antiinflammatory activities of an extract from Parkiabiglobosa used in traditional medicine in the Ivory Coast. Phytother Res 14: 635-637. 
31. Nwaehujor CO, Ezeigbo I, Udeh NE, Ezeja MI, Asuzu IU (2011) Anti-inflammatory and anti-oxidant activities of the methanolic extracts of the stalk of Parkiabiglobosa (JACQ.) BENTH. Hygeia J D Med 8: 34-40.

32. Förstermann U, Xia N, Li H (2017) Roles of vascular oxidative stress and nitric oxide in the pathogenesis of atherosclerosis. Circ Res 120: 713-735.

33. Boegehold MA (2013) The effect of high salt intake on endothelial function: reduced vascular nitric oxide in the absence of hypertension. J Vasc Res 50: 458-467

34. Lee SJ, Oh BK, Sung KC (2020) Uric acid and cardiometabolic diseases. Clin Hypertens. 26:13.

35. Kushiyama A, Nakatsu Y, Matsunaga Y, Yamamotoya T, Mori K, Ueda K et al. (2016) Role of uric acid metabolism-related inflammation in the pathogenesis of metabolic syndrome components such as atherosclerosis and nonalcoholic steatohepatitis. Mediators Inflamm 2016: 8603164.

36. Sharaf El Din UAA, Salem MM, Abdulazim DO (2017) Uric acid in the pathogenesis of metabolic, renal, and cardiovascular diseases: A review. J Adv Res 8: 537-548

\section{Figures}




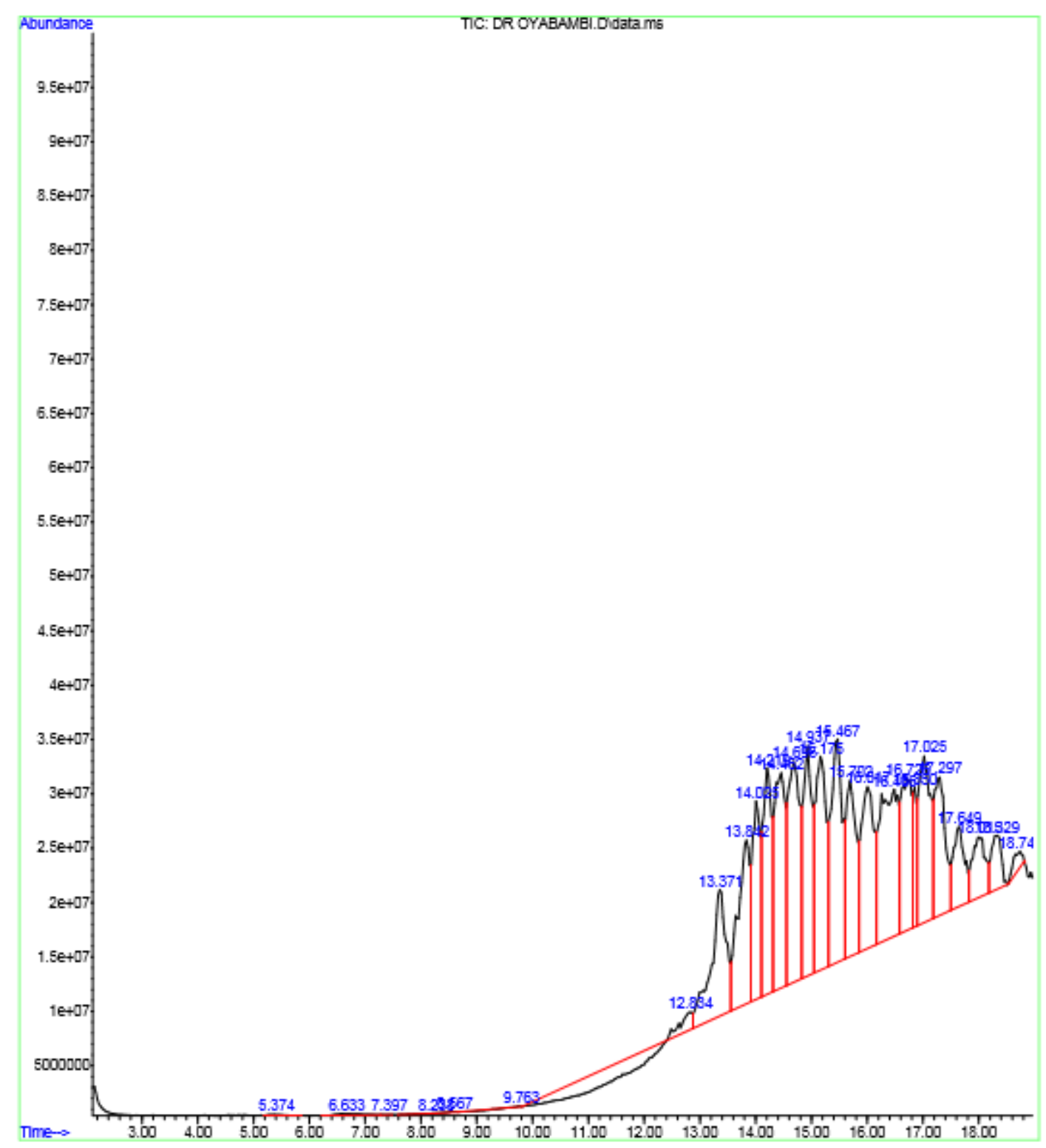

\section{Figure 1}

Chromatogram of aqueous extract of Pakia biglobosa stem bark

\section{Figure 2}

Effects of PB extract on plasma sodium (A) and potassium (B) in HSD-fed male rats. ${ }^{*} \mathrm{p}<0.05$ (vs control group), ${ }^{*} p<0.05$ (vs HSD group), ${ }^{\beta} p<0.05$ (vs HSD+Sp group)

\section{Figure 3}


Effects of PB extract on plasma triglyceride (A), total cholesterol (B), low-density lipoprotein, LDL (C) and high-density lipoprotein, HDL (D) in HSD-fed male rats.

${ }^{*} \mathrm{p}<0.05$ (vs control group), ${ }^{*} \mathrm{p}<0.05$ (vs HSD group), ${ }^{\beta} \mathrm{p}<0.05$ (vs HSD $+\mathrm{Sp}$ group)

\section{Figure 4}

Effects of PB extract on plasma uric acid (A) and cardiac uric acid (B) in HSD-fed male rats. ${ }^{*} \mathrm{p}<0.05$ (vs control group), ${ }^{\#} \mathrm{p}<0.05$ (vs HSD group), ${ }^{\beta} \mathrm{p}<0.05$ (vs HSD+Sp group)

\section{Figure 5}

Effects of PB extract on plasma adenosine deaminase (A), cardiac adenosine deaminase (B), plasma xanthine oxidase (C) and cardiac xanthine oxidase (D) in HSD-fed male rats. ${ }^{*} \mathrm{p}<0.05$ (vs control group), ${ }^{\#} \mathrm{p}<0.05$ (vs HSD group), ${ }^{\beta} \mathrm{p}<0.05$ (vs HSD+Sp group), ${ }^{\$} \mathrm{p}<0.05$ (vs HSD+PB group)

\section{Figure 6}

Effects of PB extract on plasma nitric oxide (A), cardiac nitric oxide (B) plasma endothelial nitric oxide synthase, eNOS (C), and cardiac eNOS (D) in HSD-fed male rats. ${ }^{*} \mathrm{p}<0.05$ (vs control group), ${ }^{*} \mathrm{p}<0.05$ (vs HSD group), ${ }^{\beta} p<0.05$ (vs HSD+Sp group), ${ }^{\$} p<0.05$ (vs HSD+PB group)

\section{Figure 7}

Effects of PB extract on plasma C-reactive protein, CRP (A) and cardiac CRP (B) in HSD-fed male rats. ${ }^{*} p<0.05$ (vs control group), ${ }^{*} p<0.05$ (vs HSD group), ${ }^{\beta} p<0.05$ (vs HSD+Sp group).

\section{Figure 8}

Graphical abstract 